\title{
Current updates on HIV-related pulmonary disease in children: What do radiologists and clinicians need to know?
}

\begin{abstract}
Authors:
Tracy Kilborn ${ }^{1}$

Winnie C.W. Chu ${ }^{2}$

K.M. Das $^{3}$

Bernard Laya ${ }^{4}$

Edward Y. Lee

\section{Affiliations:}

${ }^{1}$ Department of Paediatric Radiology, Red Cross War Memorial Children's Hospital, University of Cape Town, Cape Town, South Africa

${ }^{2}$ Department of Imaging and Interventional Radiology, Faculty of Medicine, The Chinese University of Hong Kong, Hong Kong
\end{abstract}

${ }^{3}$ Department of Radiology, College of Medicine and Health Sciences, United Arab Emirates (UAE) University, Al Ain, United Arab Emirates

${ }^{4}$ Institute of Radiology, St. Luke's Medical Center Quezon City and Global City, Philippines

${ }^{5}$ Department of Radiology, Boston Children's Hospital and Harvard Medical School, United States of America

\section{Correspondence to:}

Edward Y. Lee

Email:

edward.lee@childrens.

harvard.edu

Postal address:

300 Longwood Avenue, Boston, MA 02115, United States of America

Dates:

Received: 14 Aug. 2015

Accepted: 09 Oct. 2015

Published: 11 Dec. 2015

Read online:
Despite substantial advances in diagnosis and treatment, pulmonary human immunodeficiency virus (HIV) infection continues to be a major cause of morbidity and mortality in infants and children particularly those who live in developing countries. This article provides an up-to-date review on underlying etiology, often characteristic imaging findings and current management of pulmonary HIV infection in infants and children. Increased understanding of clinical and unique imaging findings of pulmonary HIV infection has a great potential for early and accurate diagnosis which, in turn, can eventually improve pediatric patient care.

\section{Introduction}

Despite substantial advances in diagnosis and treatment, pulmonary human immunodeficiency virus (HIV) infection continues to be a major cause of morbidity and mortality in infants and children particularly those who live in developing countries. This article provides an up-to-date review on etiology, imaging findings and management of pulmonary HIV infection in infants and children. Increased understanding of clinical and imaging findings of pulmonary HIV infection has a great potential for early and accurate diagnosis which, in turn, can eventually improve pediatric patient care.

\section{Human immunodeficiency virus (HIV) pulmonary infection Etiology}

The Joint United Nations Programme on HIV / AIDS (UNAIDS) 2013 global report identifies 2.9 million children infected with HIV living in sub-Saharan Africa, which is the highest incidence in the world. ${ }^{1}$ The hallmark of HIV infection is the progressive depletion of CD4+ ${ }^{+}$lymphocytes as a result of reduced production and increased destruction. ${ }^{2}$ Within the lung, direct infection of pulmonary macrophages and lymphocytes plays an important role in the pathogenesis of pulmonary disease as does an increase in immune activation. ${ }^{2}$ In addition to T cell destruction and impaired cell-mediated immune response, HIV infection is also associated with defects in humoral (B cell) immunity leading to an impaired ability to generate antigen specific response. ${ }^{3} \mathrm{HIV}$ leads to progressive immunodeficiency, opportunistic infection, AIDS related malignancy and ultimately death. The prognosis of children infected with HIV has improved since the advent of highly active antiretroviral therapy (HAART) with the emerging problem of chronic lung disease.

\section{Clinical presentation}

The HIV epidemic has resulted in an increase in childhood respiratory disease related morbidity and mortality. ${ }^{3,4}$ This is particularly evident in Africa where it is compounded by poorly implemented preventative strategies and limited access to Highly Active Antiretroviral Therapy (HAART). ${ }^{1}$ Six major respiratory disorders related to HIV infection in the pediatric patient population include: (1) pneumonia; (2) tuberculosis (TB); (3) lymphocytic interstitial pneumonia (LIP); (4) Immune Reconstitution Inflammatory Syndrome (IRIS); (5) malignancy; and (6) chronic lung disease, which are discussed in the following section.

Pneumonia remains the most common cause of hospital admission in African children infected with HIV. Pneumonia related mortality in children infected with HIV is currently 3-6 times that of non-HIV infected patients. ${ }^{5}$ Pneumocystis jirovecii (PCP) pneumonia remains a frequent underlying infectious cause in infants infected with HIV. These affected infants typically present with mild to severe acute respiratory distress and hypoxia. ${ }^{5}$ Superimposed infection with Cytomegalovirus

How to cite this article: Kilborn T, Chu, W.C.W, Das KM, Laya BF, Lee EY. Current updates on HIV-related pulmonary disease in children: What do radiologists and clinicians need to know? S Afr J Rad. 2015;19(2); Art. \#928, 5 pages. http://dx.doi.org/10.4102/sajr.v19i2.928 Copyright: @ 2015. The Authors. Licensee: AOSIS OpenJournals. This work is licensed under the Creative Commons Attribution License. 
(CMV) in HIV infected infants with PCP pneumonia is common and results in more rapid progression of underlying HIV disease. ${ }^{5,6}$ The common respiratory viruses of childhood (respiratory syncytial virus, influenza, parainfluenza and adenovirus) are more common in older children with HIV and are more likely to be complicated by bacterial pneumonia. ${ }^{4}$

Outside of infancy, Streptococcus pneumoniae is the most common cause of bacterial infection and may be recurrent in pediatric patients with HIV infection. Other frequent pathogens include Hemophilus influenzae, Staphlococcus aureus (including methicillin resistant strains), Klebsiella pneumoniae, Salmonella spp. and Eschericia coli., ${ }^{5,6}$ Factors complicating treatment of bacterial infection include reduced efficacy of vaccines and reduced antibiotic susceptibility in children infected with HIV. $^{7,8}$

In areas with a high incidence of tuberculosis such as Africa, Mycobacterium tuberculosis (TB) is an important cause of acute and chronic respiratory infection in HIV- infected children. They have an increased risk of developing complicated or disseminated disease. ${ }^{5}$ Standard TB therapy is less efficacious with lower cure rates and higher mortality. ${ }^{9}$ Co-infection with TB and HIV results in more rapid deterioration in immune function, viral replication and eventually HIV progression. ${ }^{9}$ Other fungal infection such as chronic oropharyngeal, laryngeal or oesophageal Candida albicans infection is also common and may result in dysmotility, gastro-oesophageal reflux disease and/ or aspiration and present with respiratory symptoms. ${ }^{10}$

Lymphocytic interstitial pneumonia (LIP) can still occur in HIV-infected children who have limited access to HAART $(30 \%-40 \%){ }^{11,12}$ Co-infection with Epstein Barr virus and $\mathrm{HIV}$ is thought to cause a lymphoproliferative response in multiple organs including the lungs..$^{5}$ Affected children typically present with cough, tachypnea, and mild hypoxia. Eventually, chronic lung disease may eventually develop in this pediatric patient population.

With the improved access to HAART, the recovery of the immune system may manifest as Immune Reconstitution Inflammatory Syndrome (IRIS). This presents as either deterioration of a known infection as a result of a florid immune response or as an unmasking of a previously undiagnosed subclinical infection. In Africa, pulmonary IRIS is seen most commonly with mycobacterial infection such as TB. ${ }^{13}$ However, clinical diagnosis of pulmonary IRIS must be accompanied by (1) evidence of immune restoration such as a rise in the $\mathrm{CD}^{+}{ }^{+}$count; (2) documented fall in viral load and (3) exclusion of alternative explanations of patient's symptoms such as drug resistance, non-compliance or new infection. IRIS is more common in pediatric patients with severe immunosuppression at the time of commencing HAART. ${ }^{13}$

Children with HIV also have an increased risk of malignancy most commonly Non-Hodgkin's Lymphoma. It can occur primarily in the lungs or as a result of dissemination from a distant primary focus. Kaposi's sarcoma is a common AIDSdefining malignancy. Affected pediatric patients often present with progressively worsening dyspnea, cough, and fever. ${ }^{14}$
With improved survival of HIV infected children, HIVassociated chronic lung disease has become increasingly more prevalent especially older children with lower CD4 counts and high viral loads. These children often present with chronic cough and clinical features of bronchiectasis. ${ }^{5}$ The cause may be multifactorial and includes chronic infections such as $\mathrm{TB}$, recurrent bacterial or severe viral or fungal infection. LIP, IRIS and chronic aspiration are also associated with long term sequelae. ${ }^{10}$

\section{Imaging findings}

In infants with PCP and/or CMV, the radiograph usually demonstrates varying degrees of ground glass opacification that may be symmetrical or asymmetrical (Figure 1). Short term complication such as air-leaks or long term complication such as cystic lung change (e.g., pneumatocele formation) (Figure 2) may also subsequently develop.

Imaging findings of bacterial lung infections from S. pneumonia and S. aureus are similar in both children infected with HIV and immunocompetent children. They are characterised by diffuse patchy airspace disease in bronchopneumonia and confluent airspace disease with air-bronochograms in lobar pneumonia. However, these bacterial lung infections are often more severe in children infected with HIV and result in complications such as lung abscess and empyema (Figure 3). ${ }^{5,15}$

TB is commonly encountered in children infected with HIV. On chest radiographs, TB infection typically presents with lung parenchymal disease characterised by either 'tree-in-bud' pattern small nodular opacities or consolidation (Figure 4). Mediastinal and hilar lymphadenopathy is also typically present. In comparison to immunocompetent children with TB infection, extensive lung disease with cavitation occurs more frequently in HIV-infected children (Figure 5). ${ }^{5}$ Although CT is associated with potentially harmful radiation exposure, CT

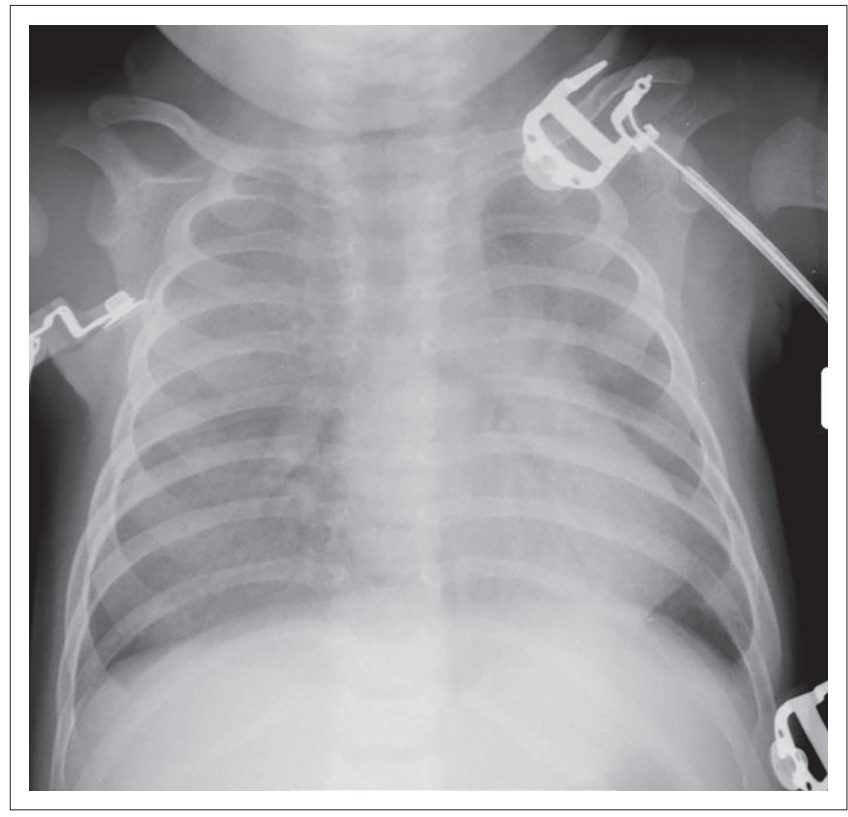

FIGURE 1: Infant boy with HIV infection who presented with respiratory distress and hypoxemia. Frontal chest radiograph shows diffuse bilateral ground glass opacification from PCP and CMV co-infection. 


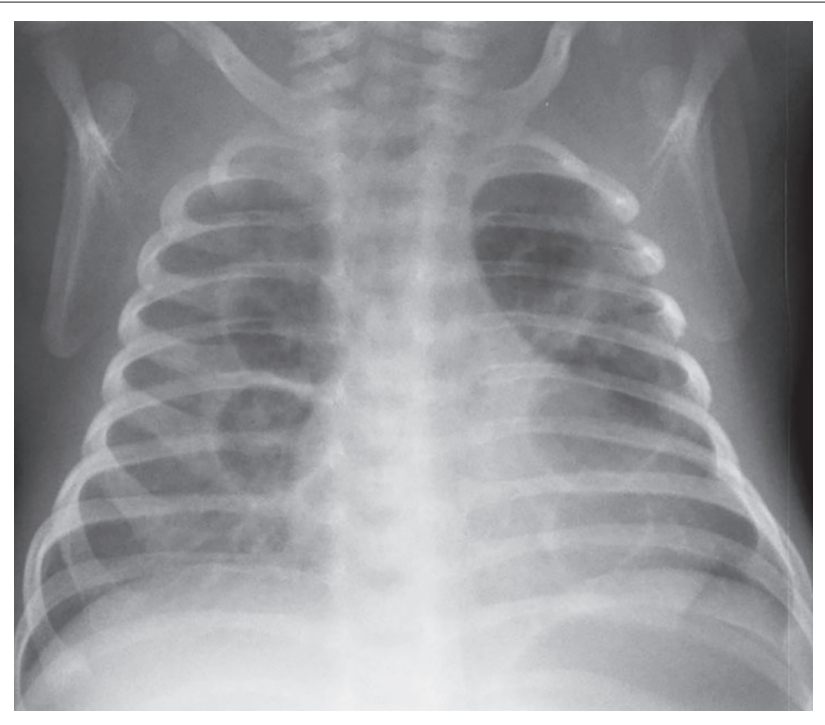

FIGURE 2: Infant girl with HIV infection and chronic PCP pneumonia. Frontal chest radiograph shows cystic changes in both lungs as a long term complication.
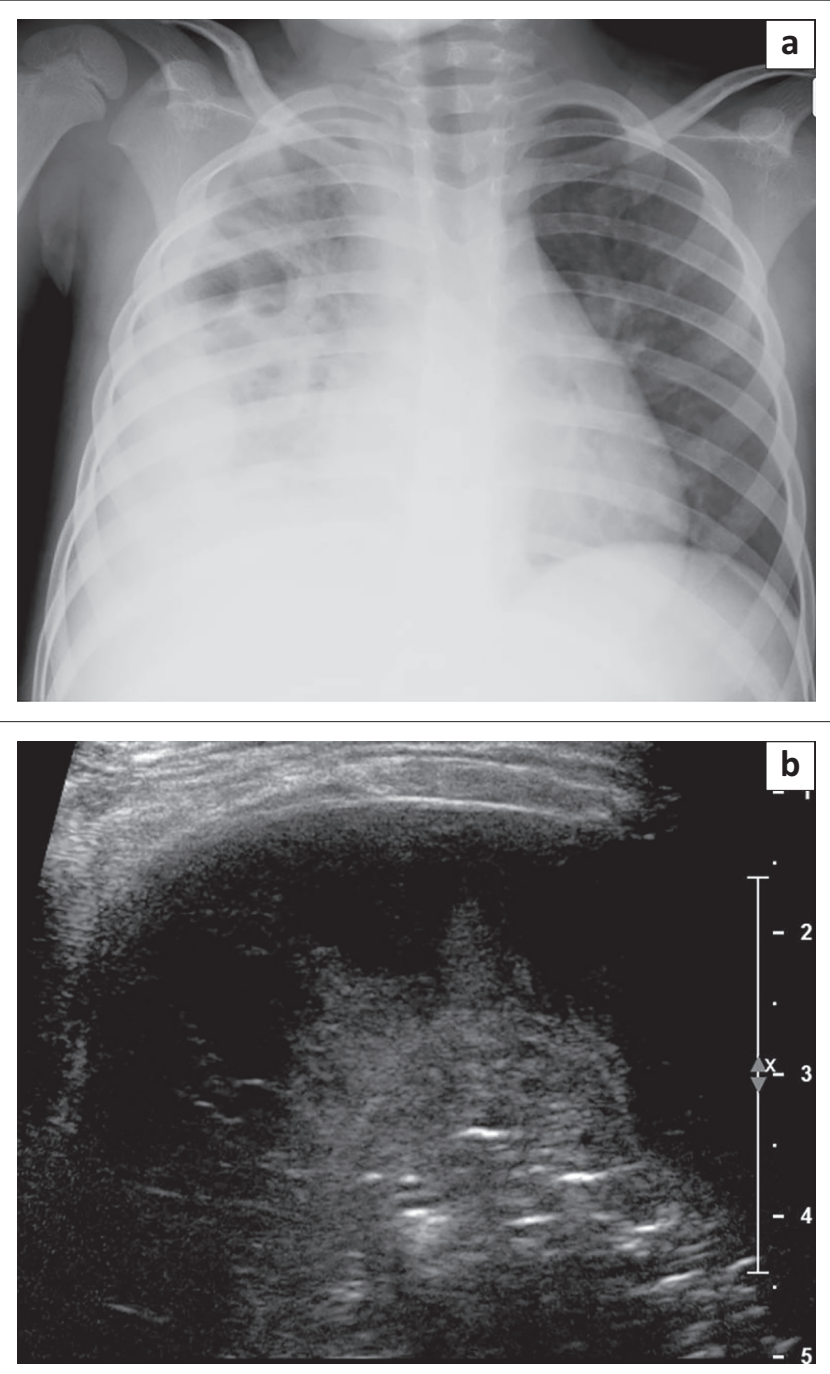

FIGURE 3: Young boy with HIV infection and S. pneumonia bacterial infection (a) Frontal chest radiograph shows extensive consolidation and effusion in the right hemithorax. (b) Ultrasound image of the right hemithorax demonstrates underlying consolidation and complex effusion with pleural thickening suggesting empyema.

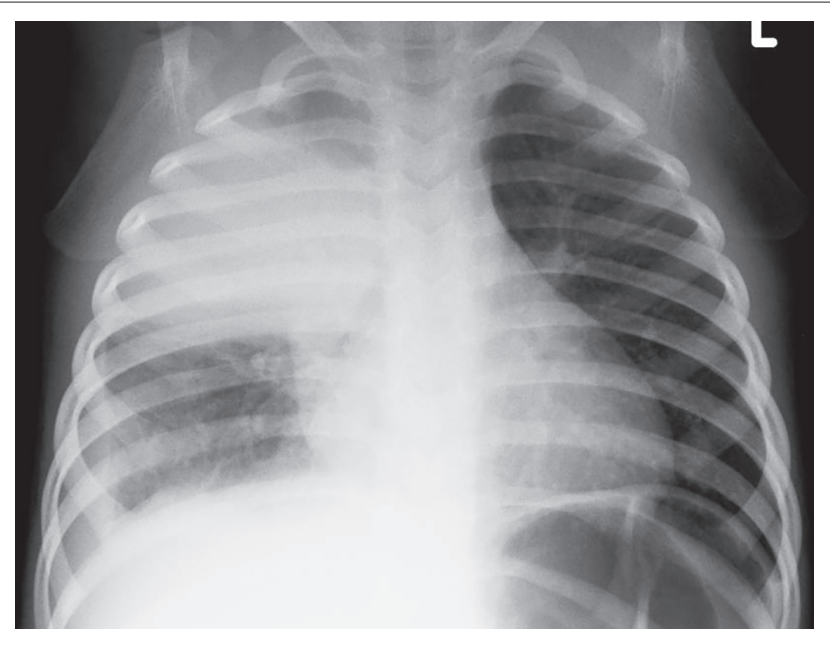

FIGURE 4: Young girl with HIV infection and TB infection. Frontal chest radiograph shows right upper lobe consolidation.
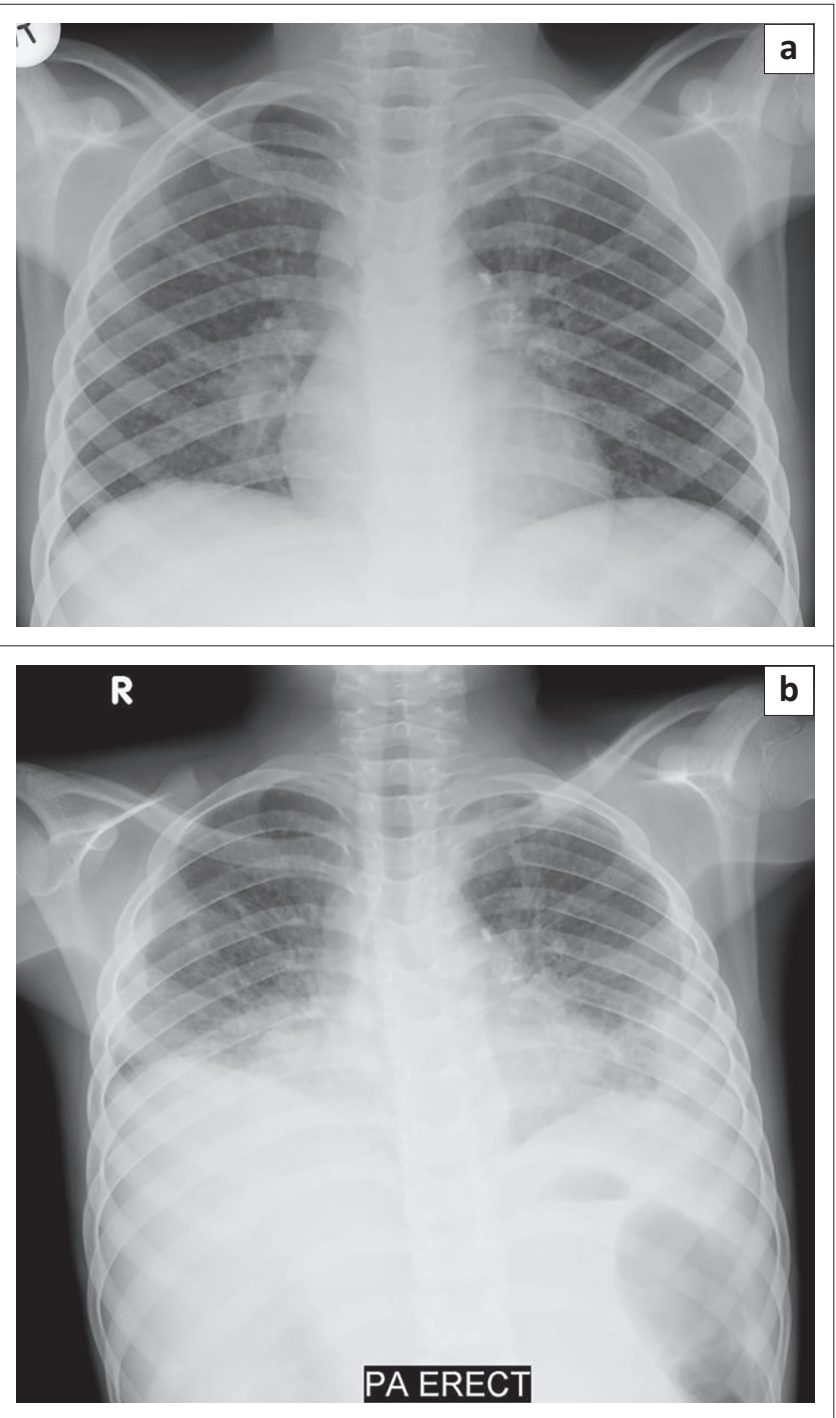

FIGURE 5: 1-year-old boy with HIV infection, severe immunosuppression and recent diagnosis of TB. (a) Frontal chest radiograph obtained while receiving HAART, shows right paratracheal and hilar adenopathy as well as diffuse small nodular opacities in both lungs. (b) Frontal chest radiograph obtained 3 weeks later demonstrates worsening mediastinal adenopathy and nodular lung opacities as well as interval development of bilateral pleural effusions despite viral suppression and improved CD4 count. Typical imaging feature of TB IRIS in children with HIV infection. 
can better detect and characterise thoracic infections from $\mathrm{TB}$. Enlarged mediastinal and hilar lymph nodes demonstrating central low attenuation and peripheral contrast enhancement should suggest TB infection in children with HIV infection especially when lung parenchymal disease is concomitantly present. ${ }^{16,17}$ With concerns about radiation exposure from CT imaging, alternative imaging modalities which are not associated with radiation exposure such as ultrasound and MRI are currently gaining favor particularly in the pediatric population.

LIP most commonly causes diffuse often symmetrical reticulo-nodular pattern opacities on chest radiographs and CT (Figure 6). ${ }^{5,10,18}$ The nodules may coalesce to produce areas of confluent airspace opacification (Figure 7). ${ }^{11}$ Peribronchial thickening alone or cysts and bronchiectasis in long-standing disease may also occur. ${ }^{10,19}$ Although lymphadenopathy may present in pediatric patients with LIP, it rarely causes tracheobronchial compression which can be often seen in the setting of TB infection. ${ }^{19}$ It is often difficult to distinguish between LIP and miliary TB on imaging alone. Parotid enlargement as a result of lymphoepithelial cysts, hepatosplenomegaly and digital clubbing are more common in LIP. On HRCT, which may improve the diagnostic accuracy, characteristic perilymphatic and subpleural nodules are often present in pediatric patients with LIP. ${ }^{15}$

Pediatric patients with HIV may also present with rare pulmonary Kaposi sarcoma, which is characterised by the perihilar airspace and reticular opacification predominately involving the lower lung zone in addition to hilar lymphadenopathy and often large pleural effusion (Figure 8). ${ }^{10}$

With improved survival of pediatric patients with HIV, chronic lung changes are now commonly seen in this

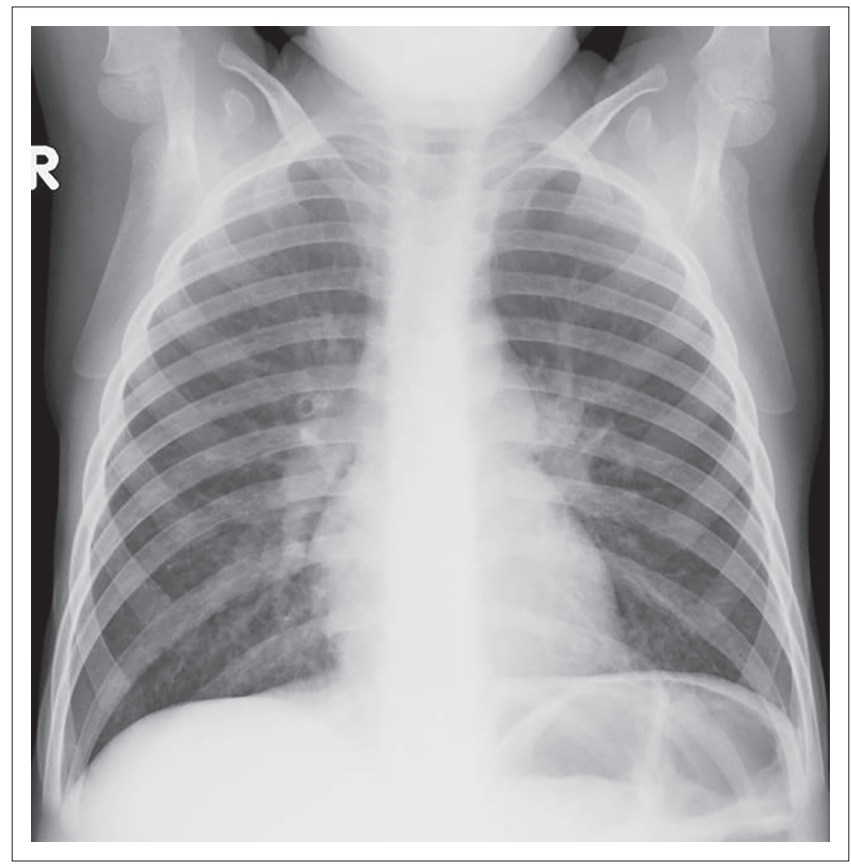

FIGURE 6: 4 year-old boy with newly diagnosed HIV. Frontal chest radiograph shows symmetric reticulo-nodular pattern opacities as well as hilar lymphadenopathy from LIP. pediatric patient population. On chest radiographs, increased bronchovascular markings, reticular and/or nodular pattern opacifications, cavities, cysts and bronchiectasis may present. ${ }^{20,21} \mathrm{CT}$ is beneficial for characterising these chronic changes as well as guiding surgical planning such as lobectomy for focal, severe, and non-reversible bronchiectasis (Figure 9).

\section{Management}

Currently, universal access to HAART using World Health Organisation guidelines has dramatically improved outcomes of children infected with HIV. Medical management currently focuses on preventing mother-to-child transmission,

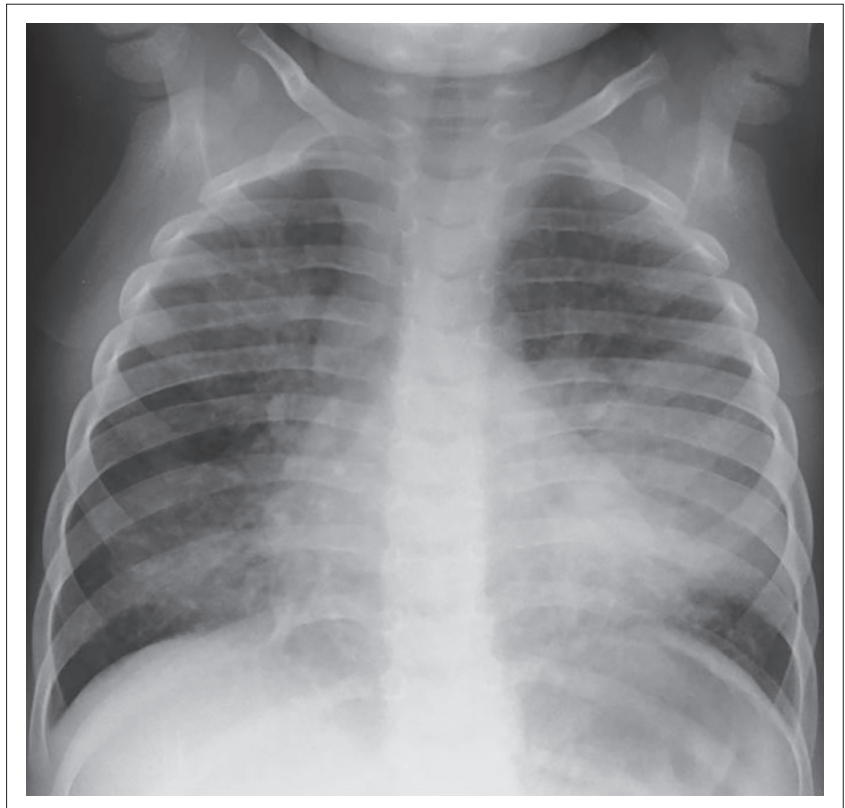

FIGURE 7: 3-year-old boy with known LIP who presented with worsening respiratory distress. Frontal chest radiograph shows bilateral reticulo-nodular pattern opacities with areas of confluent opacifications particularly in the lingual and left lower lobe.

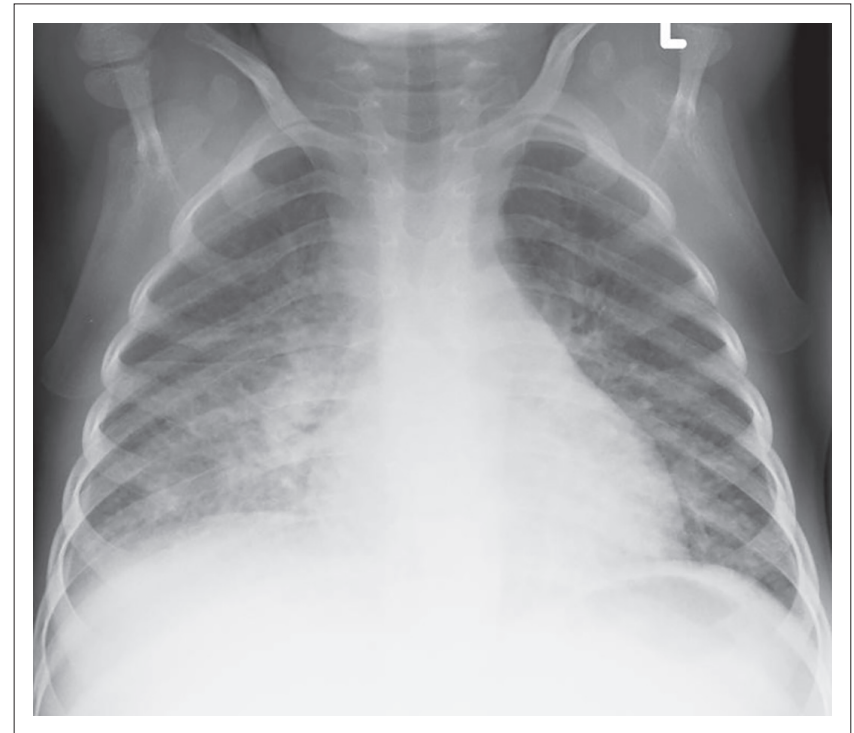

FIGURE 8: 6-year-old boy infected with HIV and severe immunosuppression who presented with a violaceous mass in the upper airway. Frontal chest radiograph shows reticulo-nodular perihilar opacities predominately located in the lower lung zones, right hilar lymphadenopathy, and bilateral effusions. The final diagnosis was pulmonary Kaposi sarcoma. 

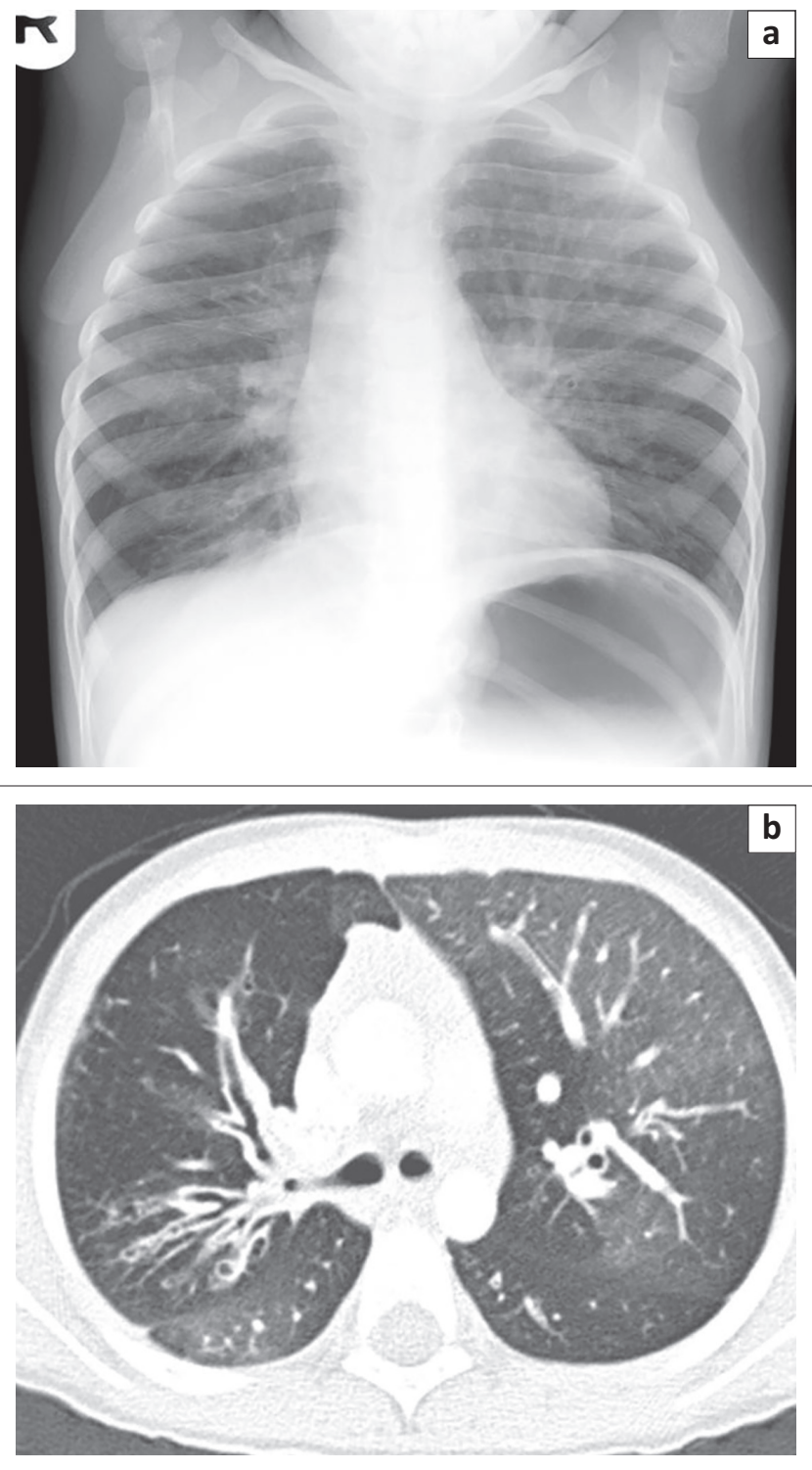

FIGURE 9: 10-year-old boy with HIV infection who presented with chronically worsening cough not responding to bronchodilator. (a) Frontal chest radiograph shows increased bronchovascular markings and reticulo-nodular opacifications. (b) Axial lung window CT image demonstrates areas of bronchiectasis and underlying small airway disease characterized by areas of mosaic attenuation due to underlying air-trapping.

screening pregnant women for HIV status, and using antiretroviral therapy during pregnancy and breast feeding period in affected mothers. It has been proven that the early diagnosis of HIV-infected infants and timely treatment with trimethoprim-sulphamethoxazole PCP prophylaxis are effective interventions. ${ }^{5}$ Unfortunately, the emerging problem of chronic lung disease can lead to severe disability in this vulnerable population. ${ }^{5,21}$

\section{Acknowledgements Competing interests}

The authors declare that they have no financial or personal relationships which may have inappropriately influenced them in writing this article.

\section{Authors' contributions}

T.K. (University of Cape Town), W.C.W.C. (University of Hong Kong), K.M.D. (College of Medicine and Health Sciences), B.L. (St. Luke's Medical Center - Quezon City and Global City), E.Y.L. (Boston Children's Hospital and Harvard Medical School) contributed equally to the writing of this article.

\section{References}

1. UNAIDS: Report on the global HIV/AIDS epidemic. [cited 2015 Jun 16]. Available from www.unaids.org

2. Maartens G, Celum C, Lewin SR. HIV infection: Epidemiology, pathogenesis, treatment and prevention. Lancet. 2014;384:258-271. PMID: 24907868, http:// dx.doi.org/10.1016/S0140-6736(14)60164-1

3. Beck JM, Rosen MJ, Peavy HH. Pulmonary complications of HIV infection. Report of the fourth NHLBI workshop. Am J Respir Crit Care Med. 2001;164:2120-2126. PMID: 11739145, http://dx.doi.org/10.1164/ajrccm.164.11.2102047

4. Graham SM. HIV and respiratory infections in children. Curr Opin Pulm Med. 2003;9:215-220. PMID: 12682567.

5. Graham SM. Impact of HIV on childhood respiratory illness: Differences between developing and developed countries. Pediatr Pulmonol. 2003;36:462-468. PMID: 14618636, http://dx.doi.org/10.1002/ppul.10343

6. Zar HJ. Chronic lung disease in human immunodeficiency virus (HIV) infected children. Pediatr Pulmonol. 2008;43:1-10. PMID: 18041077, http://dx.doi. org/10.1002/ppul.20676

7. Madhi SA, Petersen K, Khoosal M, et al. Reduced effectiveness of Haemophilus Influenzae type $b$ conjugate vaccine in children with a high prevalence of human immunodeficiency virus type 1 infection. Pediatr Infect Dis J. 2002;21:315-321. PMID: 12075763.

8. Madhi SA, Petersen K, Madhi A, Wasas A, Klugman KP. Impact of human immunodeficiency virus type 1 on the disease spectrum of Streptococcus pneumoniae in South African children. Pediatr Infec Dis J. 2000;19:1141-1147. PMID: 11144373, http://dx.doi.org/10.1097/00006454-200012000-00004

9. Hesseling $A C$, Westra $A E$, Werschkull $H$, et al. Outcome of HIV infected children with culture confirmed tuberculosis. Arch Dis Child. 2005;90:1171-1174. PMID: 15964862, http://dx.doi.org/10.1136/adc.2004.070466

10. Theron S, Andronikou S, George R, et al. Non-infective pulmonary disease in HIVpositive children. Pediatr Radiol. 2009;39:555-564. PMID: 19300991, http:// dx.doi.org/10.1007/s00247-009-1156-2

11. Pitcher RD, Lombard C, Cotton MF, Beningfield SJ, Zar HJ. Clinical and immunologica correlates of chest X-ray abnormalities in HIV-infected South African children with limited access to anti-retroviral therapy. Pediatr Pulmonol. 2014;49:581-588. PMID: 23970463, http://dx.doi.org/10.1002/ppul.22840

12. Dufour V, Wislez M, Burgot E, Mayaud C, Cadranel J. Improvement of symptomatic human immunofeficiency virus-related lymphoid interstitial pneumonia in patients receiving highly active antiretroviral therapy. Clin Infec Dis. 2003;36:e127-e130. PMID: 12746792, http://dx.doi.org/10.1086/374665

13. Zampoli M, Kilborn T, Eley B. Tuberculosis during early antiretroviral-induced immune reconstitution in HIV-infected children. Int J Tuberc Lung Dis. 2007;11:417-423. PMID: 17394688.

14. Sinfield RL, Molyneux EM, Banda K, et al. Spectrum and presentation of pediatric malignancies in the HIV era: Experience from Blantyre Malawi 1998-2003. Pediat Blood Cancer. 2007;48:515-520. PMID: 16794998.

15. George R, Andronikou S, Theron S, et al. Pulmonary infections in HIV-positive children. Pediatr Radiol. 2009;39:545-554. http://dx.doi.org/10.1007/s00247009-1194-9

16. Du Toit G, Swingler G, Iloni K. Observer variation in detecting lymphadenopathy on chest radiography. Int J Tuberc Lung Dis. 2002;6:814-817. PMID: 12234137.

17. Andronikou S, Joseph E, Lucas $S$, et al. CT scanning for the detection of tuberculous mediastinal and hilar lymphadenopathy in children. Pediatr Radiol. 2004;34:232236. PMID: 14710313.

18. Becciolini V, Gudinchet F, Cheseaux JJ, Schnyder P. Lymphocytic interstitial pneumonia in children with AIDS: High-resolution CT findings. Eur Radiol. 2001; 11:1015-1020. PMID: 11419146, http://dx.doi.org/10.1007/s003300000744

19. Oldham SA, Castillo M, Jacobson FL, Mones JM, Saldana MJ. HIV-associated lymphocytic interstitial pneumonia: Radiologic manifestations and pathologic correlation. Radiology. 1989;170:83-87. PMID: 2909125, http://dx.doi org/10.1148/radiology.170.1.2909125

20. Rabie H, Marais BJ, van Toorn R, et al. Important HIV-associated conditions in HIVinfected infants and children. S Afr Fam Pract. 2007;49:19-23. http://dx.doi.org/1 0.1080/20786204.2007.10873538

21. Norton KI, Kattan M, Sunil Rao J, et al. Chronic radiographic lung changes in children with vertically transmitted HIV-1 infection. Am J Roentgenol. 2001;176:15531558. PMID: 11373231, http://dx.doi.org/10.2214/ajr.176.6.1761553 